\title{
REFLEXÕES SOBRE O ESTÁGIO/ PRÁTICA DE ENSINO NA FORMAÇÃO DE PROFESSORES
}

\author{
Reflections upon the apprenticeship/practice of \\ teaching in teachers' development
}

\begin{abstract}
Maria Socorro Lucena Lima
Professora e pesquisadora em Didática e Estágio da Universidade Estadual do Ceará (UECE), e Doutora pela FEUSP, Fortaleza, Ceará - Brasil, e-mail: socorro_lucena@uol.com.br
\end{abstract}

\section{Resumo}

As reflexões apresentadas neste texto procuram perceber, entre o escrito e o vivido, o papel do Estágio/Prática de Ensino nos cursos de formação de professores, percorrendo os seguintes pontos: um convite à reflexão pedagógica sobre o contexto; universidade e escola - diferentes culturas que se encontram no Estágio; ensinar e aprender a formação docente e lições do Estágio. Tais reflexões permitemnos perceber a transitoriedade desta atividade enquanto ritual de passagem para o exercício da profissão. À luz dos conceitos atualmente abordados pela literatura na área, destacamos o Estágio curricular como eixo privilegiado de formação docente e um campo de conhecimento. Como lócus de conhecimento com vistas à aproximação investigativa da realidade tem na pesquisa sobre a prática o centro dessa formação.

Palavras-chave: Formação de professores; Estágio; Prática de ensino.

Rev. Diálogo Educ., Curitiba, v. 8, n. 23, p. 195-205, jan./abr. 2008 


\section{Abstract}

The reflections presented in this text focus on how to realize, between what has been written and lived, the training/ teaching practice role at teachers instructions courses through the folowing points: an invitation aiming at the education reflection about context; university and school - diferent cultures which get closer at training period; teach and learn the teacher instruction and training according to all its content. These reflections let us know how this activity occurs while a step for reaching the professional degree. Theoretically based on the current educational literature, we pointed the curricular period of training out as an important teaching instruction axis as well as a knowledge field. By taking training period as a knowledge place looking forwards to an investigative approach of reality it finds on research about practice, the formation basis.

Keywords: Teacher's formation; Training period; Teaching practice.

É triste ver esse homem, guerreiro, menino, com as marcas do seu tempo por sobre seus ombros, eu vejo que ele berra, eu vejo que ele sangra a dor que traz no peito, pois ama e ama.

(Gonzaguinha)

O tempo de magistério, com atuação na disciplina Prática de Ensino/ Estágio Supervisionado, na universidade, tem nos ensinado muitas lições. Aprendizagens que nos levam a refazer continuamente nossa prática e a descobrir novos jeitos de conviver com os desafios deste componente curricular nos cursos de formação de professores e seu papel na vida dos estagiários. Estaremos percorrendo os cinco pontos de reflexão que apresentamos a seguir, procurando fazer um debate entre o escrito e o vivido, entre o dito e o feito:

- um convite à reflexão pedagógica sobre o contexto;

- universidade e escola: diferentes culturas que se encontram no Estágio;

- ensinar e aprender a formação docente;

- lições do estágio;

- somos sempre estagiários da vida.

Esperamos que nossa conversa possa trazer elementos para o debate e que abra caminhos para que o Estágio curricular possa ser o eixo da formação e um campo de conhecimentos pedagógicos. Lembramos que os cursos de

Rev. Diálogo Educ., Curitiba, v. 8, n. 23, p. 195-205, jan./abr. 2008 
Reflexões sobre o estágio/prática de ensino na formação de professores

licenciatura precisam ser espaços onde se pede "licença" para o exercício do magistério - daí a importância do Estágio na identificação com a profissão de professor e a necessidade dos diálogos pedagógicos entre os professores formadores e alunos. Diz a canção popular que: "Guerreiros são pessoas tão fortes, tão frágeis, guerreiros são meninos no fundo do peito. Precisam de um descanso, precisam de um remanso, precisam de um sonho que os torne refeitos" (GONZAGUINHA). Que este momento seja para nós - guerreiros do magistério - uma pausa para a troca, para o sonho comum, para a utopia da organização de um estágio melhor.

\section{Um convite à reflexão sobre o contexto}

Para que possamos compreender formação docente na atualidade e suas tendências investigativas e metodológicas, que incluem o estudo dos saberes necessários à prática do professor, é importante que busquemos os seus determinantes. Destacamos dentre eles: os princípios do lema "aprender a aprender", constante no Relatório da Comissão Internacional da Organização das Nações Unidas para a Educação, a Ciência e a Cultura (UNESCO). Criada em 1993 e presidida por Jaques Delors, trouxe conseqüências para os chamados novos paradigmas da educação no campo da formação docente. A comissão definiu as responsabilidades individuais e sociais do processo educativo com base em seis pistas de reflexão: educação e cultura; educação e cidadania; educação e coesão social; educação, trabalho e emprego; educação e desenvolvimento; educação, investigação e ciência.

A comissão aponta os males do final do século XX como os progressos econômico e científico, que foram repartidos de forma desigual, elevando o desemprego e a exclusão social; e indica a educação como um meio de amenizar os problemas e afastar os riscos das questões sociais provocadas pela globalização. A partir dessa premissa, afirma ser necessário pensar políticas educacionais que promovam a construção de um mundo melhor, mediante a renovação de uma vivência democrática real para o desenvolvimento humano sustentável; a compreensão entre os povos; e a solução das crises sociais. Ao professor, cabe o papel de ajudar seus alunos a encontrar, organizar e gerir o saber (DELORS, 2001, p. 145).

Mudando o conceito de professor, mudam os rumos da sua formação que são mobilizados pelo discurso ideológico e a implementação de políticas controladas por propostas de gestão e avaliação do sistema de ensino. Nesse contexto, o professor muitas vezes nem percebe os determinantes que norteiam e sustentam sua vida profissional e as mudanças que nela estão ocorrendo, mesmo quando estão freqüentando um curso de formação docente.

Rev. Diálogo Educ., Curitiba, v. 8, n. 23, p. 195-205, jan./abr. 2008 
Ao mesmo tempo, a sociedade moderna tem exigido dos trabalhadores da educação desempenhos cada vez mais qualificados e eficazes para conviver com as contradições e os problemas da sociedade, dita "globalizada", que se refletem na escola. Por esses motivos, entendemos a necessidade de investigar e analisar as atividades de Estágio/Prática de Ensino, considerando-as como um dos importantes eixos dos cursos de formação de professores e como espaço propiciador da reflexão. Assim, a prática reflexiva e dialogada com a teoria estaria sendo realizada por meio da pesquisa e dos seus desdobramentos. Reiteramos a importância de que os envolvidos nas atividades do Estágio/Prática de Ensino possam levantar elementos de compreensão sobre o trânsito dos alunos estagiários entre a cultura acadêmica e a cultura escolar, no sentido de identificar a cultura do magistério e as aprendizagens dela decorrentes.

Há uma perspectiva de ritual de passagem intermediando as práticas de Estágio/Prática de Ensino. Seu caráter passageiro faz com que ele seja sempre incompleto, porque é no efetivo exercício do magistério que a profissão docente é aprendida de maneira sempre renovada. Defendemos este componente curricular como espaço de aprendizagem da profissão docente e de construção da identidade profissional, que permeia as outras disciplinas da formação, no projeto pedagógico dos cursos de formação, mas é o lócus da sistematização da pesquisa sobre a prática, no papel de realizar a síntese e a reflexão das vivências efetivadas.

\section{Universidade e escola: diferentes culturas que se encontram na prática de ensino/ estágio supervisionado}

Os grandes desafios e contradições que envolvem a operacionalização do Estágio/Prática de Ensino na Universidade nem sempre são estudados e compreendidos por formadores e formandos. O trabalho de planejamento, negociação com as escolas recebedoras, desenvolvimento e avaliação de atividades, concentrados no período letivo de um semestre, muitas vezes dificulta a visão do todo. Dessa forma, pode ficar despercebida uma questão fundamental, que está na base de muitos dos nossos descontentamentos e conflitos no decorrer do Estágio que é o movimento de aproximação de duas instituições de ensino, cada uma trazendo valores, objetivos imediatos, cultura e relações de poder diferentes, com o objetivo de realizarem um trabalho comum: a formação de professores. No meio destes dois campos de força está o estagiário, preocupado em cumprir os requisitos acadêmicos propostos pelo professor - orientador da disciplina e transitar de maneira satisfatória pela escola na busca de aprendizagens sobre a profissão.

$\mathrm{Na}$ busca de compreender essa questão, recorremos aos conceitos de campo, de habitus (BOURDIEU, 2003, p. 64) e de cultura docente. Se considerarmos o campo como espaço de poder, tanto da universidade como da

Rev. Diálogo Educ., Curitiba, v. 8, n. 23, p. 195-205, jan./abr. 2008 
Reflexões sobre o estágio/prática de ensino na formação de professores

escola, podemos perceber a complexidade que envolve o estágio e as práticas executadas no seu interior. A nossa preocupação é quanto às aprendizagens e às lições que podem ser retiradas dessa passagem uma vez que, nesse enfoque, o estágio pode ser comparado a uma ponte, na qual os estagiários exercem suas atividades na tensão desse jogo de forças.

A idéia de habitus preconizada por Bourdieu (2003, p. 64) se revela nas práticas, completando um movimento de interiorização de estruturas exteriores. Tanto na universidade como na escola, o estagiário vai conviver com tais esquemas e práticas. Muitas vezes, acontecem problemas e equívocos no decorrer do Estágio, que são agravados pelo fato de os estagiários não terem clareza das relações que se estabelecem entre as instituições e as pessoas que por elas transitam. O espaço da escola de educação básica, recebedora dos estagiários, torna-se, dessa forma, o espaço de encontro das culturas dos alunos, dos formadores e dos estagiários.

É importante lembrar que cada escola tem um jeito especial, específico de conduzir o seu cotidiano e sua organização e de se posicionar diante das questões e desafios que surgem. De acordo com Farias (2002, p. 110), no interior da escola se fazem acordos, negociações e se estabelecem regras próprias que regulamentam tanto seu funcionamento burocrático, como as concepções, crenças e valores das pessoas que fazem seu coletivo.

Para Apple (1989, p. 82), os estudos ligados à economia, à classe social, à cultura e aos processos de escolarização ajudam na compreensão sociológica e crítica sobre a escola. É preciso atentar para o fato de que a cultura vivenciada é trazida para a escola e entra em confronto com o conhecimento formal trazido pelo currículo. Assim, é na sala de aula que acontece o embate entre os conhecimentos das disciplinas, conhecimentos do currículo e a cultura vivida por alunos e professores.

Ajudam-nos ainda nesta compreensão os estudos de Fourquin (1993, p. 10) pela explicação que não é possível ver a cultura como algo imutável. Para o autor, a escola é um caldeirão de culturas, espaço de efervescência cultural, identificado na forma de organização do trabalho escolar e nos elementos que a constituem: hierarquia, visão de mundo, tipo de formação, concepção de ciência e espaços de poder. Diante de toda a cultura que mobiliza a escola, é necessário que o estagiário possa entendê-la como um grupo social interativo, no qual acontece o fenômeno educacional em suas contradições e possibilidades.

Quando trazemos os estudos sobre cultura escolar, realizados pelos autores anteriormente citados, para o panorama do ensino superior, indagamos sobre o mesmo processo acontecendo no espaço universitário, onde está situado o trabalho de formadores e as atividades dos estagiários. Quais valores, crenças, preocupações, espaços de poder da Universidade? Qual o lugar da pesquisa e da docência? De que maneira cada curso de licenciatura lida com a profissão docente na teoria e na prática?

Rev. Diálogo Educ., Curitiba, v. 8, n. 23, p. 195-205, jan./abr. 2008 


\section{Ensinar e aprender a profissão docente}

Pensar sobre os cursos de formação para o magistério em suas perspectivas teóricas e práticas leva-nos a refletir sobre o trabalho docente, a profissão do professor na sociedade e no momento histórico em que estamos inseridos. Implica na construção de conhecimentos, no estabelecimento de um diálogo pedagógico com os alunos, com os livros, com os saberes da docência, com o papel social da escola, da universidade, e as políticas que regem a educação, entre outras questões. Assim indagamos: É possível ensinar o ofício de professor? Qual o espaço da prática na formação para o magistério? E da teorização da prática? Que lições de estágio podem ser aprendidas pelos alunos dos cursos de licenciatura?

Os processos de identificação com a profissão docente podem acontecer por meio das atividades realizadas por formadores e formandos. Compreendemos que as propostas metodológicas revelam uma percepção do valor atribuído ao ensino, bem como certas idéias em relação aos processos de ensinar e de aprender. De acordo com a concepção de conhecimento que norteia a sua prática pedagógica, o professor de Estágio passa a articular as atividades com os alunos. Dentro de suas limitações e possibilidades de tempo, espaço e condições objetivas de trabalho da universidade, dos estagiários e das escolas recebedoras, o professor assume o papel de orientador, que é o responsável por um componente curricular no contexto das disciplinas do curso. Já o olhar atento do estagiário aproveitará a oportunidade de contato com a escola para descobrir valores, organização, funcionamento dela, bem como a vida e o trabalho dos seus professores e gestores.

Pinto e Fontana (2002, p. 116), quando falam sobre o trabalho escolar e a produção do conhecimento, por ocasião das atividades de Práticas de Ensino, advertem para o encontro e o confronto que acontecem entre os professores da escola de educação básica, os professores da universidade e os educadores em formação. Consideram o Estágio e a Prática de Ensino uma grande convergência de saberes, histórias de vida e experiências individuais e coletivas. Cientes desse confronto e refletindo sobre eles, o estagiário poderá situar-se e entender os acontecimentos tirando deles as lições necessárias à sua formação. As autoras fazem perguntas que versam, em primeiro lugar, sobre os saberes dos estagiários, da escola, e da universidade, indagando sobre os laços coletivos que unem tais saberes. Refletem ainda sobre os valores, as contradições, as lutas próprias de cada segmento que se encontra no espaço do Estágio, destacando a necessidade de um reconhecimento de papéis e de um diálogo pedagógico, que estabeleça a compreensão da escola como recebedora e formadora dos estagiários.

Há grande necessidade de que o estagiário encontre o seu lugar na escola, dentro das relações de que participa e que o Estágio inclua no seu projeto uma proposta de mudança de enfoque, sugerindo que os alunos reconheçam sua

Rev. Diálogo Educ., Curitiba, v. 8, n. 23, p. 195-205, jan./abr. 2008 
Reflexões sobre o estágio/prática de ensino

na formação de professores

própria presença e o seu papel no local do estágio, em vez de focalizarem suas atenções apenas nos fracassos encontrados. Dessa forma, o período do Estágio/ Prática de Ensino, mesmo que transitório, pode tornar-se um exercício de participação, de conquista e negociação sobre as aprendizagens profissionais que a escola pode proporcionar.

O que dá sentido às atividades práticas dos cursos de formação é esse movimento que acontece a partir das leituras, práticas, saberes e conhecimentos, que se confrontam e se intercruzam. As atividades de reflexão e registro poderão auxiliar no entendimento das questões relativas às contradições acontecidas no trabalho educativo. Entre o escrito e o vivido estão: cultura, relações de trabalho, classe social, etnia, idade e campos de poder, entre outros aspectos.

Pimenta e Anastasiou (2002, p. 197) afirmam que o significado social que os professores atribuem a si mesmos e à educação escolar exerce papel fundamental nos processos de construção da identidade docente. Para as autoras, esta identidade se constrói no confronto entre as teorias e as práticas, na análise sistemática das práticas à luz das teorias, na construção de teorias. Essa compreensão permite analisar o estágio como espaço de mediação reflexiva entre a universidade, a escola e a sociedade.

Compreendemos, assim, que a identidade pode ser analisada, tanto na perspectiva individual, como na dimensão coletiva. Enquanto a primeira é constituída pela experiência pessoal e as vivências individuais, que expressa o sentimento de originalidade, a segunda se constrói no interior dos grupos, configurando-se socialmente uma identidade coletiva.

\section{Lições do estágio/prática de ensino}

As aprendizagens decorrentes do estágio poderá ser uma postura metodológica utilizada pelos professores e alunos que trabalham com o Estágio/ Prática de Ensino. A clareza de que cabe ao estagiário a tarefa de fazer da experiência com o trabalho de campo deverá ser um passo significativo para a construção da identidade profissional docente e a compreensão do processo educacional acontecido na escola e da cultura do magistério. Que pontos de reflexão podem ajudar nos percursos de estágio?

- Lições aprendidas na localização da escola: Onde a escola está situada? Em que parte da cidade? Como é sua localização urbana? Como se caracteriza a vizinhança, o comércio, os serviços de saúde, a segurança, entre outros?

- Lições aprendidas na chegada: entre nossas atividades com os estagiários, destacamos o portão da escola e a chegada dos alunos. Em trabalho anterior - (LIMA 2002, p. 61) - destacamos que a porta ou o portão da escola representa para

Rev. Diálogo Educ., Curitiba, v. 8, n. 23, p. 195-205, jan./abr. 2008 
o estagiário uma oportunidade de reflexão e questionamentos. Quais as marcas da sociedade atual estão na entrada da escola? Como é o prédio? Quem controla o portão e de que maneira? Como são os transeuntes que por aí trafegam? Quem passa, o que passa e deixa de passar pelo portão da escola? Demorar-se no portão da escola é experiência de compreensão do que acontece lá dentro. O panorama que se descortina, a partir do espaço escolar, pode trazerà tona alguns aspectos que talvez nunca tenhamos observado: a vida da comunidade, a movimentação na frente da escola, costumes, preferências, manifestações de multiculturalismo. O entorno da escola e o movimento que acontece na rua, no quarteirão, a chegada dos alunos, dos pais e de funcionários e de outras pessoas que compõem esse fluxo.

- Lições de aprendidas entre o dito e o feito, entre o escrito e o vivido: é importante a compreensão da escola dentro do sistema educacional e da implantação e implementação das políticas vigentes. A análise sobre o papel social da escola, por meio do levantamento de dados, registro e documentos oficiais, pode trazer valiosas informações para uma visão de conjunto das necessidades e problemas, das possibilidades e avanços da instituição escolar. Trata-se do estagiário aprofundar os conhecimentos teóricos e práticos sobre a escola, não mais de forma descomprometida, mas com o olhar de professor. O diagnóstico da escola é uma das atividades relevantes para a compreensão da realidade. Para Libâneo (2006, p. 178), "o estudo e a reflexão na escola sobre a proposta dos PCN atrelamse a outro componente muito importante na vida escolar: a organização e a forma da gestão da instituição de ensino". O cruzamento de dados, feito entre o que a literatura pedagógica diz sobre a escola, o que dizem os documentos oficiais e a realidade registrada nas observações e entrevistas, oferece um importante estudo comparativo de compreensão reflexiva e crítica da realidade.

- Lições do Projeto Político Pedagógico da Escola: vale a pena perceber o Projeto Pedagógico em processo de operacionalização, ou seja, a comunidade escolar, vivenciando aquilo que foi debatido e decido por ela, no coletivo. A idéia de projeto como ação está ligada a dois componentes essenciais: a questão educativa e o trabalho coletivo. De acordo com Valle (1999, p. 05), todo projeto parte de uma tomada de posição diante da realidade natural, social e humana. Dessa forma, é uma maneira de superar o contexto existente, criando o novo pela razão, emoção e ação. O contato do estagiário com o Projeto PolíticoPedagógico e com outras modalidades de registro sobre gestão e desempenho, como PDE (Plano de Desenvolvimento da Escola), poderá trazer elementos de análise e reflexão. No entanto, tirar do papel o que está registrado não é fácil. É preocupante a burocratização do Projeto Político-Pedagógico e o distanciamento dos professores das decisões coletivas da escola. O estudo dos registros e das práticas coletivas realizadas, encontradas no espaço da instituição, também são oportunidades de relevantes lições para os estagiários.

Rev. Diálogo Educ., Curitiba, v. 8, n. 23, p. 195-205, jan./abr. 2008 
Reflexões sobre o estágio/prática de ensino na formação de professores

- Lições decorrentes da interação de saberes: o estudo das relações estabelecidas no encontro/confronto de professores da universidade, docentes da escola de educação básica e estagiários, cada um com os seus valores, visões de mundo e experiências diferentes, abre espaço para descobertas: Qual o papel da universidade? Qual o papel da escola? Quem é o estagiário? Que cultura de magistério permeia o Estágio?

- Lições dos procedimentos de investigação: concordamos com Charlot (2005, p. 147) quando insiste que a escola pública deve ser defendida como um direito, o que acarreta obrigações para com ela. Para o autor supracitado, tal educação requer transformações das práticas pedagógicas, que devem ser acompanhadas por uma formação de professores, instrumentalizada pela pesquisa. Cabe ao ensino superior manter de maneira interligada, as atividades de ensino, de pesquisa e as profissionalizantes. Para Libâneo (2006, p. 410), a aprendizagem da pesquisa implica na promoção de atividades em que o aluno supere suas dificuldades de buscar informações, analisá-las, relacioná-las com os conhecimentos anteriores, dando-lhes significado.

- Lições da escola em movimento: Como os alunos circulam no espaço escolar? Que posturas caracterizam a equipe gestora, os funcionários, os professores e os alunos? Como são os procedimentos de entradas, saídas, atividades no pátio de recreio, quadra de esportes, corredores, banheiros, portas das salas de aula, cantina?

- Lições da observação e atuação na sala de aula: é necessário que o estagiário aprenda a exercitar um olhar pedagógico e atento para entender o que há de estranho nas coisas comuns. Quando estamos atentos para o movimento da sala e seu cotidiano, podemos verificar o que não se aprende, o que se ensina, a interação entre os alunos, as possibilidade e contradições entre alunos e professores.

\section{Somos sempre estagiários da vida: considerações finais}

A observação do contexto e a investigação do cotidiano escolar abrem um leque de outras questões de investigação/intervenção que podem se constituir como aprendizagem da profissão docente. Formadores e formandos atentos aos nexos e relações que se estabelecem entre a universidade e a escola, e destas com a profissão magistério e seus profissionais, terão a oportunidade de descobrir formas de se reconhecerem como estagiários da vida e aprendizes da prática docente.

A cultura do magistério inclui-se na cultura escolar e pode ser compreendida como jeito de ser e de estar na profissão. Dessa forma, precisamos entender melhor a realidade inserida nessa diversidade cultural.

Rev. Diálogo Educ., Curitiba, v. 8, n. 23, p. 195-205, jan./abr. 2008 
Acreditamos no Estágio como lócus de formação do professor reflexivo-pesquisador, de aprendizagens significativas da profissão, de cultura do magistério, de aproximação investigativa da realidade e do seu contexto social. Reafirmamos o nosso conceito de Estágio, como campo de conhecimento, que envolve estudos, análise, problematização, reflexão e proposição de soluções sobre o ensinar e o aprender, tendo como eixo a pesquisa sobre as ações pedagógicas, o trabalho docente e as práticas institucionais, situadas em contextos sociais, históricos e culturais (PIMENTA; LIMA, 2004, p. 61).

O estágio curricular é uma passagem. Quando as perguntas e dificuldades básicas começam a ser superadas após algumas discussões, registros e relatórios, a carga horária prevista para o estágio chega ao seu fim, antes mesmo que encontremos todas as respostas para as perguntas iniciais, ingressamos em outros desafios acadêmicos e novas perguntas e reflexões vão surgindo.

Ao reelaborar este processo, lembramos que em outras fases da vida somos também estagiários, como nos ensinava uma das nossas alunas em seus registros: "Somos sempre estagiários da vida." Estamos sempre despreparados para as perguntas e os desafios pessoais e profissionais que surgem em nossa vida. Partindo do princípio de que ser aprendiz da vida é ser estagiário, queremos chamar novamente a canção de Gonzaguinha para terminar nossa reflexão: "É triste ver esse homem, guerreiro, menino, com as marcas do seu tempo por sobre seus ombros." A letra da música termina dizendo: "Não dá pra ser feliz!" Voltando à epígrafe inicial desse texto, sabemos que dá para ser feliz, sim: "porque guerreiros são pessoas", que precisam não apenas de um sonho que os tornem refeitos. Este sonho, em que se procura refletir, compreender e buscar superação, é chamado de utopia, pelo mestre Paulo Freire.

\section{REFERÊNCIAS}

APPLE, M. W. Educação e poder. Tradução Maria Cristina Monteiro. Porto Alegre: Artes Médicas, 1989.

BOURDIEU, Pierre. A economia das trocas simbólicas. Tradução de Sergio Miceli e outros. São Paulo: Perspectiva, 2003.

CHARLOT, Bernard. Relação com o saberformação de professores e globalização: questões para a educação hoje. Porto Alegre: Artmed, 2005.

DELORS, Jaques. Educação: um tesouro a descobrir. São Paulo: Cortez, 2001.

Rev. Diálogo Educ., Curitiba, v. 8, n. 23, p. 195-205, jan./abr. 2008 
Reflexões sobre o estágio/prática de ensino

na formação de professores

FARIAS, Isabel Maria Sabino. Inovação e mudança: implicações sobre a cultura dos professores. 2002. 260 f. Tese. (Doutorado em Educação) Faculdade de Educação, Universidade Federal do Ceará, Fortaleza, 2002.

FOURQUIN, Jean-Claude. Escola e cultura. Porto Alegre: Artes Médicas, 1993.

LIBÂNEO, José Carlos. Organização e a gestão da escola: teoria e prática. 3. ed. Goiânia: Alternativa, 2006.

Docência no ensino superior: compromissos e desafios da prática pedagógica. In: ENCONTRO DA AVALIAÇÃO E PLANEJAMENTO PEDAGÓGICO - EAPP, 10 e 11., 2006, Salvador. Anais... Salvador: UCSAL, 2006. p. 1-12.

LIMA, Maria Socorro Lucena (Org.). Dialogando com a escola. Fortaleza: Demócrito Rocha, 2002.

PIMENTA, Selma Garrido; ANASTASIOU, Léa das Graças Camargo. Docência no ensino superior. São Paulo: Cortez, 2002. (Coleção Docência em Formação).

; LIMA, Maria Socorro Lucena. Estágio e docência. São Paulo: Cortez, 2004. (Coleção Docência em Formação).

PINTO, Ana Lúcia Guedes; FONTANA, Roseli Aparecida Cação. Trabalho Escolar e Produção de Conhecimentos. In: MACIEL, Lizete Shizue Bomura; SHIGUNOV, Neto; SHIGUNOV, Alexandre (Org.). Desatando os nós da formação docente. Porto Alegre: Mediação, 2002. p. 5-22.

SANTOS, Milton. Técnica, espaço, tempo, globalização e meio técnico: científico e informal. São Paulo: Hucitec, 1996.

VALLE, Lílian do. Espaços e tempos educativos na contemporaneidade: a Paidéia democrática como emergência do singular e do comum. In: CANDAU, Vera Maria (Org.). Cultura, linguagem e subjetividade no ensinar e aprender. Rio de Janeiro: DP\&A, 1999. p. 97-110.

Recebido: 30/08/2007

Received: 08/30/2007

Aprovado: 05/11/2007

Approved: $11 / 05 / 2007$

Rev. Diálogo Educ., Curitiba, v. 8, n. 23, p. 195-205, jan./abr. 2008 